\title{
Congenital Hypergonadotropic Hypogonadism
}

National Cancer Institute

\section{Source}

National Cancer Institute. Congenital Hypergonadotropic Hypogonadism. NCI

Thesaurus. Code C120161.

Ovarian or testicular dysfunction associated with high levels of gonadotropins, that is present at birth. 